\title{
EFFECT OF OBESTATIN ON CARDIOVASCULAR SYSTEM IN TYPE II DIABETIC RAT MODEL
}

\author{
Mohammed H. Ibrahim, Nawal K. Gerges, Nadine A. Raafat, Shaimaa A. Hadhoud \\ Physiology department, Faculty of Medicine, Zagazig University
}

\author{
Corresponding Author: \\ Nadine Ahmed Raafat \\ tel: 01228942090
}

\section{INTRODUCTION}

O bestatin (OB) is a novel peptide (23 amino acid), released in the oxyntic mucosa of the stomach $(\mathbf{1}, \mathbf{2}, 3)$. Zhang et al. (4) firstly described it as a ghrelin-associated peptide, encoded by the same gene as ghrelin, and called

\section{ABSTRACT}

Background: Obestatin (OB) is a novel anorexiogenic peptide produced in the stomach. It has been shown to regulate glucose and lipid metabolism. However, its potential role in cardiovascular control is still not clear and controversial.

Aim of the work: To evaluate the in vivo and in vitro effects of Obestatin on cardiovascular system in both normal and diabetic rats. Also, to identify the possible mechanism of its action.

Material and methods: 40 healthy male albino rats weighing 180-200 gm. were used and divided into two main groups: In vivo experiments subdivided into normal $(\mathrm{n}=10)$ and Type II Diabetes induced groups $(n=10)$ In which heart rate and blood pressure were recorded before and after OB (100 Mg/kg body weight) injection, In vitro experiments subdivided into normal $(n=10)$ and Type II Diabetes induced group $(n=$ $10)$ in which the effect of OB $(1 \mathrm{nmol} / \mathrm{l})$ alone and its effect in presence of $\beta$-blocker propranolol (30Mmol/1) and $\alpha$ blocker prazosin (3Mmol/1) on amplitude and frequency of cardiac contractility were studied , also effects of $\mathrm{OB}$ alone $(100 \mathrm{pmol} / \mathrm{l})$ and in presence of $\operatorname{LNAME}(0.3 \mathrm{Mmol} / \mathrm{l})$ on contraction induced by phenylephrine $(10 \mathrm{Mmol} / \mathrm{L})$ of isolated thoracic aorta. Type II Diabetes induced by feeding rats for two weeks a high-fat diet $(58 \%$ fat, $25 \%$ protein, $17 \%$ carbohydrates as percentage of total calories). On day 13, rats were given a single intraperitoneal injection of streptozotocin ( $25 \mathrm{mg} / \mathrm{kg}$ body).

Results: Obestatin injection showed no significant difference on blood pressure and heart rate in both normal and diabetic rats, However in vitro studies showed that $\mathrm{OB}$ has both positive inotropic and chronotropic effects on isolated heart of both normal and diabetic rats which were blocked by propranolol but not by prazocin. Moreover, OB produced significant vascular relaxation of isolated rat thoracic aorta of the normal group which was attenuated by L-NAME in normal rats. However, the relaxation effect of $\mathrm{OB}$ was much weaker in diabetic rats and was blocked by L-NAME.

Conclusion: Obestatin improves cardiac function and exerts vasodilator effects via nitric oxide (NO) release, so it may be decrease systemic vascular resistance in type II diabetes.

Key words: Obestatin, type II diabetic rats, propranolol, prazocin, isolated thoracic aorta. 
Ghrelin was known to have role in cardiovascular and sympathetic regulations (7), As improving cardiac function (8), inhibiting the apoptosis of myocardial cell (9), decreasing peripheral artery resistance (10), and has protecting role against ischemia-reperfusion injury (11).

However, the relationship between obestatin and cardiovascular control was not clear and the previous studies aimed to explore the correlationships between obestatin and cardiovascular regulation were scarce and controverse. (7).

Iglesias et al. (12) found that exogenous obestatin had no effect on cell cycle or viability in the HL-1 cardiac muscle cell line and thought that obestatin was not a relevant metabolic or viability modifier for cardiomyocytes as ghrelin . However, Sazdova et al. (13) reported that obestatin could directly enhance the effect of myocardial $\beta$ adrenergic signaling. Furthermore, Alloatti's group found that obestatin could activate some antiapoptotic signaling pathways and protect cardiac cell against myocardial injury and apoptosis induced by ischemia-reperfusion (14).

Type II diabetic patients have risk of cardiovascular disease mortality more than double compared with that in age-matched subjects. Also, Stroke events and all manifestations of coronary heart disease, myocardial infarction (MI), sudden death, and angina pectoris are at least twofold more common in patients with type 2 diabetes than in nondiabetic individuals (15) Recently, Aragno et al. (2) found that $\mathrm{OB}$ could exert a beneficial effect against the alterations of contractility and $\beta$ adrenergic response in the heart of streptozotocin-treated diabetic rats.

OB was also supposed to play a role in blood pressure regulation in both rats and humans, however, The relationship between OB and blood pressure regulation was indeterminate (7).

Anderwald-Stadler et al. (16) firstly reported that fasting plasma $\mathrm{OB}$ level was negatively correlated with systolic blood pressure in insulin-resistant humans. However, Ren et al. (17) also found that fasting plasma OB level was significantly higher in pregnant women with pregnancy-induced hypertension compared with normotensive pregnant women. Furthermore, Li et al. (18) found that fasting plasma OB level was positively correlated with systolic blood pressure in spontaneously hypertensive rat and was significantly higher compared with that of Wistar-Kyoto rat. In contrary, Li et al. (19) reported that intravenous bolus of OB did not change the blood pressure level in spontaneously hypertensive rats. In addition Li et al. (20) showed no significant difference in fasting $\mathrm{OB}$ level between hypertension and control.

On the face of this controversy, this study was done to answer many confliction or unknown about the relationship between OB and cardiovascular system and also to identify the possible mechanism of action in normal and diabetic rats.

\section{Animals}

\section{MATERIALS \& METHODS}

This study was carried out on a total number of 40 adult male albino rats weighing 180-200 gm. They were obtained from the animal house from faculty of veterinary medicine of Zagazig University. The animals were kept in steel wire cages (7-8 cage) in the animal house in faculty of medicine of Zagazig University under hygienic conditions. Animals were fed standard chow diet which consists of (25.8\% protein, $62.8 \%$ carbohydrates and $11.4 \%$ fat (total $12.6 \mathrm{KJ} / \mathrm{g}$ ) $\mathbf{( 2 1 )}$ prior to the dietary manipulation for induction of type II diabetes. and had free access to water, kept at room temperature and were maintained on a $12 \mathrm{~h} \mathrm{light/dark} \mathrm{cycle.}$

The experimental protocol was approved by physiology department and by local medical ethics committee in faculty of medicine of Zagazig University (Institutional Review Board, IRB).

Protocol and Experimental groups:

Animals were divided into two main groups: In vivo studies $(\mathbf{n}=\mathbf{2 0})$ subdivided 
into : normal and Diabetic induced groups $(n=10)$ : In each group the heart rate and blood pressure were recorded before and after single OB injection in a dose of $100 \mathrm{Mg} / \mathrm{kg}$ body weight (19) (Sigma chemical co., St.louis USA, dissolved in distilled water.). In vitro studies $(\mathbf{n}=\mathbf{2 0})$ also subdivided into normal and Diabetic induced groups $(n=10)$ : In each group the heart was excised and used for study the effect of $\mathrm{OB}$ alone $(1 \mathrm{nmol} / \mathrm{l})$ (13) and in presence of $\beta$-blocker propranolol Hcl ( 30 $\mathrm{Mmol} / \mathrm{l})$ and $\alpha$ blocker prazocin (3Mmol/1) (sigma chemical, st.louis, MO, sigma - Aldrich, USA ). (13). on amplitude and frequency of cardiac contractility in basal conditions. Also, in each group the thoracic aorta was excised and used for Study the effect of OB alone (100 $\mathrm{pmol} / \mathrm{l})(\mathbf{2 1})$ and in presence of L-NAME nitric oxide synthase inhibitor $(0.3 \mathrm{Mmol} / \mathrm{l})$ (Fluka chemei Gmbh Sigma -Aldrich , Switzerland) (21) on top of phenylephrine (sigma chemical, st.louis, MO, sigma - Aldrich, USA) (10 $\mathrm{Mmol} / \mathrm{l})$ (21) induced contraction of isolated rat thoracic aorta.

\section{Methods:}

\section{Rat model of type II diabetes}

To induce diabetes, 20 Rats were fed for two weeks a high-fat diet (58\% fat, $25 \%$ protein, $17 \%$ carbohydrates as percentage of total calories) (total $23.4 \mathrm{KJ} / \mathrm{g}$ ), respectively in the form of cotton seed oil added to the laboratory chow diet (23). On day 13, rats were fasted overnight and given a single intraperitoneal injection of streptozotocin (25 mg/kg body) dissolved in $0.2 \mathrm{mmol} / \mathrm{L}$ sodium citrate, at $\mathrm{ph}$ 4.5 the following morning, and the high-fat diet feeding was continued for a further week (24). The rats were provided with oral $10 \%$ glucose solution after 6 hours of streptoztocin administration for the next 48 hours.

After the three weeks, type II diabetes was confirmed by measurement of blood glucose level in each animal (blood was sampled from the tail vein ) with the one touch Glucomoter (25) and rats with blood glucose levels more than $250 \mathrm{mg} / \mathrm{dl}$ were selected for the experiment (26).
Measurement of Blood Pressure (BP) according to Zorniak et al. (27) and Parasuraman and Raveendran (28)

An overnight fasted $(8-10 \mathrm{~h})$ each rat was anesthetized with urethane $(1200 \mathrm{mg} / \mathrm{kg})$, and placed on a suitable rodent none electrically conductive surgical table. The skin on the ventral side of the neck is shaved and disinfected. The skin was carefully cut open $(1.5-2 \mathrm{~cm})$, and a slit incision was made in the platysma muscles. The trachea was identified, small incision was made on the cartilage tissue, and the tracheostomy was performed using a small piece of tracheal intubation tube.

One side of the carotid artery was separated from the adjacent connective tissue, and its cephalic end was tied and the cardiac end was clamped with a bulldog clamp and cannulated using a heparinized cannula $(0.5 \mathrm{IU} / \mathrm{ml}$ in saline).

The other end of the cannula connected to a three-way stopcock connected to the pressure transducer and a syringe filled with heparinized saline. Then the carotid artery cannulation site was tied with a thread without obstructing the blood flow in the carotid cannula. Then bulldog clamp was released slowly, ensuring that there was no bleeding at the cannulation site.

After cannulation, the animal is connected to the Power Lab (AD Instruments Pty Ltd, Australia) to record the BP. The pressure cuff of the sphygmomanometer was connected to the pressure transducer. Then, the pressure transducer is checked by inflating to a known pressure level. The calibration between the voltage (millivolts) and the pressure $(\mathrm{mmHg}$ ), and the results are automatically calculated by power Lab software.

After recording the baseline blood pressure, obestatin was injected by removing the saline filled Syringe and placing the obestatin filled one instead in a dose of $(100 \mathrm{mg} / \mathrm{kg})$, then blood pressure was measured again $(\mathbf{2 9}, \mathbf{2})$.

\section{Recording ECG and heart rate}

Three-lead bipolar ECG was used in electrocardiography. Positive, negative, and reference electrocardiogram electrodes were 
placed at the left foreleg, right foreleg, and left thigh, respectively, to record electrocardiogram $(30,31,28)$.

Isolated heart preparations Animals were sacrificed by decapitation, then rapid thoracotomy was performed and the heart was rapidly excised by cutting the great vessels , placed in Krebs Ringer bicarbonate solution which has the following composition (NaCL $6.895 \mathrm{gm} / \mathrm{L}, \mathrm{KCl} 0.350 \mathrm{gm} / \mathrm{L}, \mathrm{CaCl} 20.280$ $\mathrm{gm} / \mathrm{L}, \mathrm{NaH} 2 \mathrm{Po} 40.160 \mathrm{gm} / \mathrm{L}, \mathrm{MgSo} 40.290$ $\mathrm{gm} / \mathrm{L}$,NaHco3 2.1 gm/L, Glucose $2.1 \mathrm{gm} / \mathrm{L}$ ) (32) gassed with 95\% O2 and 5\% co $2, \mathrm{PH}=7.4$ then cleaned from lung tissue and pericardium , was applied to aortic cannula at $37 \mathrm{C}$ and perfused by langendorff's technique (AD Instruments Pty Ltd, Australia).

The heart was allowed to stabilize for 5 minutes before any manipulation (33). An isotonic lever was attached to the ventricular apex and used to record the developed tension (amplitude of contraction) on power lap connected to computer.

Cardiac performance was assessed by recording Amplitude of contraction ( $\mathrm{mm}$ ) and Frequency (beat/minute) before and after any drug given:

OB was applied and then after recording its effect tand wash, each of blockers (propranolol and prazocin) applied separately first to record their effects then $\mathrm{OB}$ and blocker applied together.

\section{Isolated aortic strips preparations:}

After excision of the thoracic aorta, about 3 $\mathrm{cm}$ segment was carefully dissected from connective tissue and fat and. Then the strip was cut spirally without damaging the endothelium. Rings were suspended between a force transducer and a fixed support in organ bath chambers containing $5 \mathrm{~mL}$ modified Krebs-Henseleit buffer $(\mathrm{NaCl6} .970 \mathrm{gm} / \mathrm{L}, \mathrm{KCl}$ $0.350 \mathrm{gm} / \mathrm{L}, \mathrm{NaH} 2 \mathrm{Po} 40.140 \mathrm{gm} / \mathrm{L}, \mathrm{MgSO} 4$ $0.280 \mathrm{gm} / \mathrm{L}, \mathrm{NaHCO} 32.1 \mathrm{gm} / \mathrm{L}$, Glucose 2 $\mathrm{gm} / \mathrm{L}, \mathrm{CaCl} 2$ (25\% solution) $0.93 \mathrm{ml} / \mathrm{L}$ (34) $(\mathrm{PH}=7.4$ and bubbled with carbogen $95 \% \mathrm{O} 2$ and $5 \% \mathrm{CO} 2$ ), at $37^{\circ} \mathrm{C}$. Data were recorded using Power Lab. Vessels were held at a resting tension of $1 \mathrm{~g}$ (which was found to be optimal in preliminary experiments) and allowed to equilibrate for at least one hour before any manipulation $(\mathbf{3 5}, \mathbf{2 2})$.

Following washout and re-equilibrium, a bolus dose of phenylephrine (PE, $10 \mathrm{mmol} \cdot \mathrm{L}-1)$ was added to produce maximal contraction. Obestatin (100 Pmol/l) (22) was applied alone and in presence of L-NAME on top of steady contractions induced by PE.

Sampling of blood: Blood samples (were taken from the cannula after measuring BP and tracing ECG and also after scarification of rats for in vitro experiments) and were allowed to clot for 2 hours at room temperature before centrifuging for 20 minutes at approximately $500 \mathrm{rpm}$. The separated serum was stored at $20^{\circ} \mathrm{C}$.

Serum analysis: Insulin levels: according to Temple et al (36) using INS-EASIA, KAP1251 (BioSource Europe S.A).

-Glucose levels: according to Tietz (37) using glucose enzymatic (GOD-PAP)liquizyme rat Kits (Biotechnology, Egypt).

Calculation of Homeostasis model assessment of insulin resistance (HOMA-IR) according to the equation of Sun et al. (38) modification on Matthews et al. (39) [HOMA$\mathrm{IR}=$ insulin $(\mu \mathrm{U} / \mathrm{mL}) \times$ glucose $(\mathrm{mg} / \mathrm{dL}) / 405]$.

Statistical analysis: Results were presented as mean \pm S.D. Differences between in vivo and in

vitro normal and diabetics groups were investigated using paired and unpaired t.tests. $\mathrm{P}$

value $<0.05$ was considered statistically significant. The statistical analysis is done by using SPSS program (20) (SPSS Inc. Chicago, IL,USA).

\section{RESULTS}

Table (1) illustrates serum glucose ( $\mathrm{mg} / \mathrm{dL})$, insulin (MIU/L) and HOMA-IR parameters, regarding serum glucose and HOMA-IR, they were significantly $(\mathrm{P}<0.001)$ higher in diabetic rats $(276 \pm 23.78 \& 8.9 \pm 1.25$ respectively) vs. normal $(76.1 \pm 10.86 \& 2.31 \pm 0.37$ respectively), however no significant difference $(\mathrm{p}>0.05)$ in insulin levels between both groups.

In vivo studies results: Table (2), and traces (1.2.3 \&4) show: systolic blood pressure SBP 
(mmhg), diastolic blood pressure DBP (mmhg), mean arterial pressure MAP (mmhg) and heart rate HR (beat / minute ) with $\mathrm{OB}$ injection in normal and diabetic groups; there was no significant difference $(p>0.05)$ between mean values of SBP, DBP, MAP and HR after OB injection as compared with baseline in both normal and diabetic groups.

In vitro studies results: Table (3) and traces $(5,6,7,8,9 \& 10)$ illustrates effects of OB alone and in presence of propranolol and prazosin on amplitude and frequency of cardiac contractility of isolated rat heart in normal and diabetic groups. As expected, mean value of amplitude and frequency of basal contractility in diabetic group was significantly lower ( $\mathrm{P}$ $<0.001, \mathrm{p}<0.01$ respectively ) than that of normal group ,and also mean value of amplitude and frequency after obestatin were significantly higher $(\mathrm{p}<0.001)$ than that of before obestatin in both groups, interestingly, in diabetic rats effects of $\mathrm{OB}$ on both amplitude and frequency were significantly $(\mathrm{P}<0.001)$ higher than that in normal group as $\%$ of change in mean value of amplitude and frequency changed from $(72.4 \pm 19.86 \&$ $35.34 \pm 10.66$ respectively) in normal rats to (188.97 $\pm 29.17 \& 98.8 \pm 25.4$ respectively) in diabetic group. in addition ,these positive inotropic and chronotropic effects of obestatin were completely abolished by propranolol ( $\mathrm{p}>$ 0.05 ) in both groups, however prazocin didn't alter OB effects as in normal rats \% of change in mean value of amplitude and frequency with prazosin +OB were $(68.5 \pm 21.1 \& 32.48 \pm 9.17$ respectively) and that with $\mathrm{OB}$ alone were (72.4 $\pm 19.86 \& 35.34 \pm 10.66$ respectively) also, in diabetic rats $\%$ of change in mean value of amplitude and frequency with prazosin $+\mathrm{OB}$ were $(157.85 \pm 42.5 \& 91.03 \pm 15.5$ respectively) and that with OB alone were $(188.97 \pm 29.17 \&$ $98.8 \pm 25.4$ respectively).

However, Mean value of amplitude and frequency with propranolol alone was significantly lower $(p<0.001)$ than that of before propranolol, however no change of mean value of amplitude and frequency after prazosin alone $(\mathrm{p}>0.05)$ in both groups.

Table (4) \& traces $(11,12,13 \& 14)$ : concerning effects of $\mathrm{OB}$ alone and in presence of LNAME on Amplitude of PE induced contraction of isolated rat thoracic aorta, it was found that OB significantly $(p<0.001)$ has relaxing effect on aorta of both normal and diabetic, $\%$ of relaxation in normal rats is significantly more than that in diabetic ones, moreover, L-NAME partially reduced the relaxation effect of $\mathrm{OB}(\mathrm{p}<0.01)$ in normal however greatly block this effect in diabetic rats. 
Table (1) : mean \pm SD of serum glucose, serum insulin and HOMA-IR in normal \&diabetic rats

\begin{tabular}{lll}
\hline & Normal rats $(\mathbf{n = 2 0})$ & Diabetic rats $(\mathbf{n = 2 0})$ \\
\hline Serum glucose $(\mathrm{mg} / \mathrm{dL})$ & $76.1 \pm 10.86$ & $276 \pm 23.78^{\mathrm{a}}$ \\
\hline serum insulin $(\mathrm{MIU} / \mathrm{L})$ & $12.33 \pm 0.99$ & $12.88 \pm 1.27^{\mathrm{NS}}$ \\
\hline HOMA-IR & $2.31 \pm 0.37$ & $8.9 \pm 1.25^{\mathrm{a}}$ \\
\hline
\end{tabular}

Table (2):mean \pm SD of SBP, DBP, MAP and HR with OB injection in normal and diabetic group

\begin{tabular}{|c|c|c|c|c|c|c|c|c|}
\hline & \multicolumn{2}{|c|}{ SBP } & \multicolumn{2}{|c|}{ DBP } & \multicolumn{2}{|c|}{ MABP } & \multicolumn{2}{|c|}{ Heart rate } \\
\hline & Control & $\overline{\mathbf{O B}}$ & control & $\mathrm{OB}$ & control & $\mathrm{OB}$ & Control & $\mathrm{OB}$ \\
\hline Normal $(n=10)$ & $88.1 \pm 12.63$ & $\begin{array}{l}86.6 \pm 11.2 \\
4^{\mathrm{Ns}}\end{array}$ & $\begin{array}{l}46.6 \pm 10 . \\
98\end{array}$ & $\begin{array}{l}44.8 \pm 11.55 \\
\mathrm{Ns}\end{array}$ & $\begin{array}{l}67.05 \pm 13.2 \\
3\end{array}$ & $\begin{array}{l}65.9 \pm 14.0 \\
6^{\mathrm{Ns}}\end{array}$ & $\begin{array}{l}291.3 \pm 26 . \\
5\end{array}$ & $290.9 \pm 28.19^{\mathrm{Ns}}$ \\
\hline Diabetic $(n=10)$ & $92.12 \pm 7.69$ & $\begin{array}{l}94.37 \pm 7.4 \\
\text { NS }\end{array}$ & $51.2 \pm 7.1$ & $50.7 \pm 6.9^{\mathrm{NS}}$ & $64.7 \pm 5.06$ & $\begin{array}{l}65.2 \pm 3.6 \\
\mathrm{Ns}\end{array}$ & $291.6 \pm 7.2$ & $291.2 \pm 7.6^{\mathrm{NS}}$ \\
\hline
\end{tabular}

$$
\text { Ns = non-significant }(P>0.05) \text { vs. control }
$$

Table (3):mean \pm SD of amplitude and frequency of cardiac contractility of isolated rat heart with OB, Propranolol and prazocin in normal and diabetic groups.

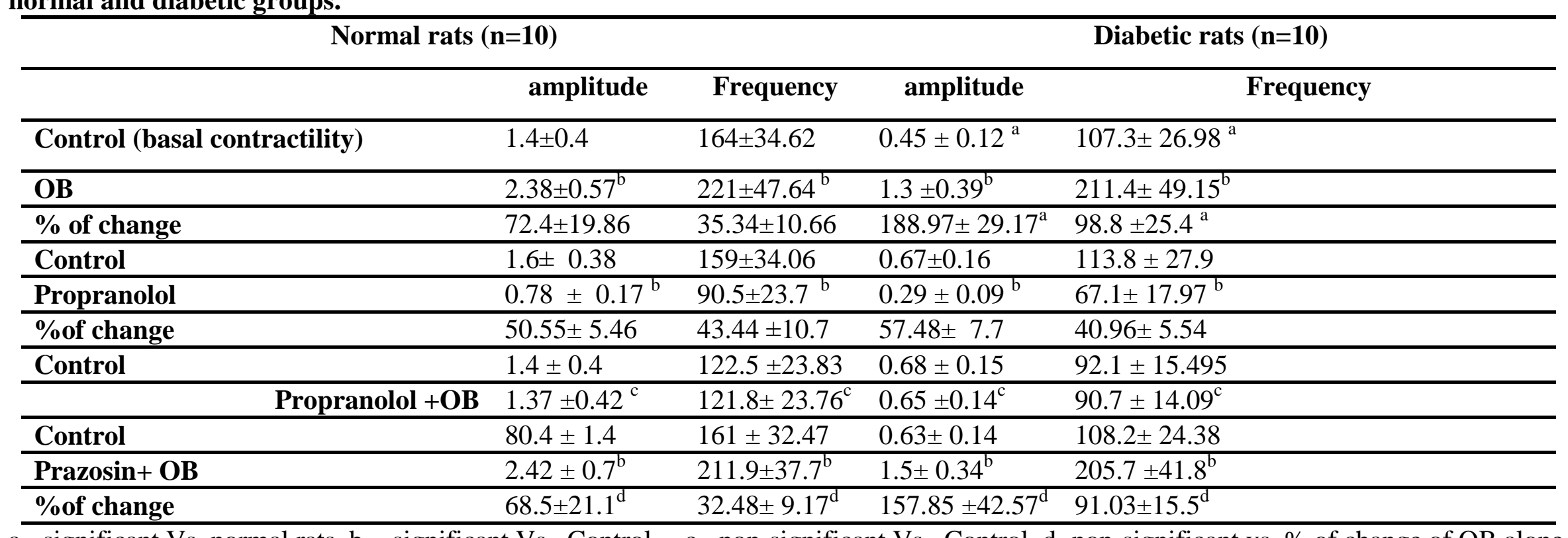

$\mathrm{a}=$ significant Vs. normal rats, $\mathrm{b}=$ significant Vs. Control , $\mathrm{c}=$ non-significant Vs. Control, $\mathrm{d}=$ non-significant vs. \% of change of OB alone 
Table (4):mean \pm SD of Amplitude of PE induced contraction of isolated rat thoracic aorta (in mm) with OB and LNAME in normal \&diabetic groups.

\begin{tabular}{lcr}
\hline & Normal rats $(\mathbf{N}=\mathbf{1 0})$ & Diabetic rats $(\mathbf{N}=\mathbf{1 0})$ \\
\hline Control & $9.2 \pm 2.4$ & $8.5 \pm 1.5$ \\
\hline OB & $0.91 \pm 0.23^{\mathrm{a}}$ & $7.63 \pm 1.24^{\mathrm{a}}$ \\
\hline \% of relaxation & $90.02 \pm 0.84$ & $9.95 \pm 2.53^{\mathrm{c}}$ \\
\hline Control & $9.55 \pm 1.98$ & $7.25 \pm 2.17$ \\
\hline OB and L-NAME. & $8.79 \pm 1.81^{\mathrm{a}}$ & $7.21 \pm 2.14^{\mathrm{NS}}$ \\
\hline \% of relaxation & $8.01 \pm 1.79 \mathrm{~b}$ & \\
\hline
\end{tabular}

$\mathrm{a}=$ significant Vs. control, $\mathrm{b}=$ significant Vs. \% of relaxation of OB alone, $\mathrm{c}=$ significant with \% of relaxation of normal, NS= non-significant Vs. Control 


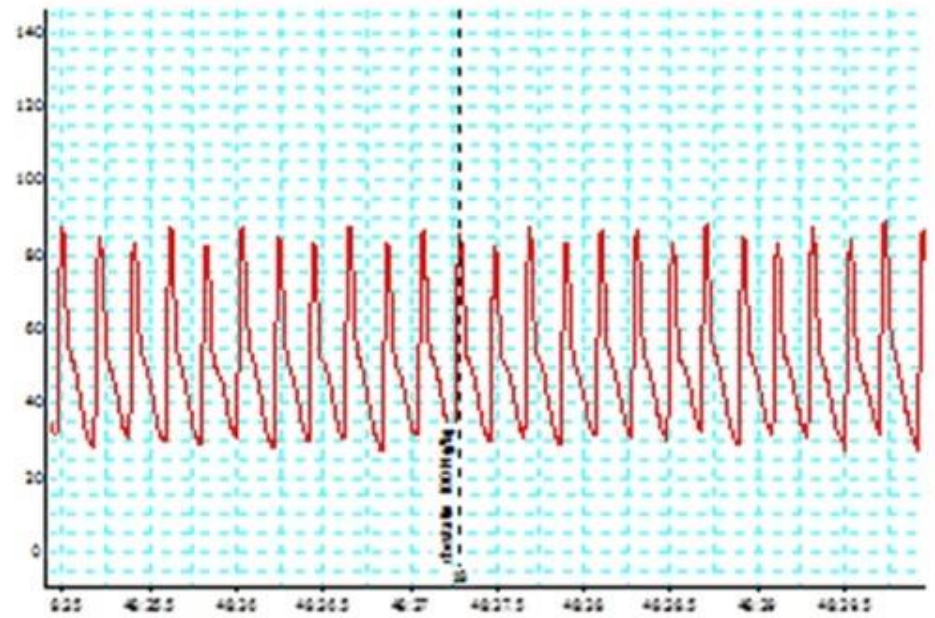

Tracing (1): Blood pressure of normal rat.

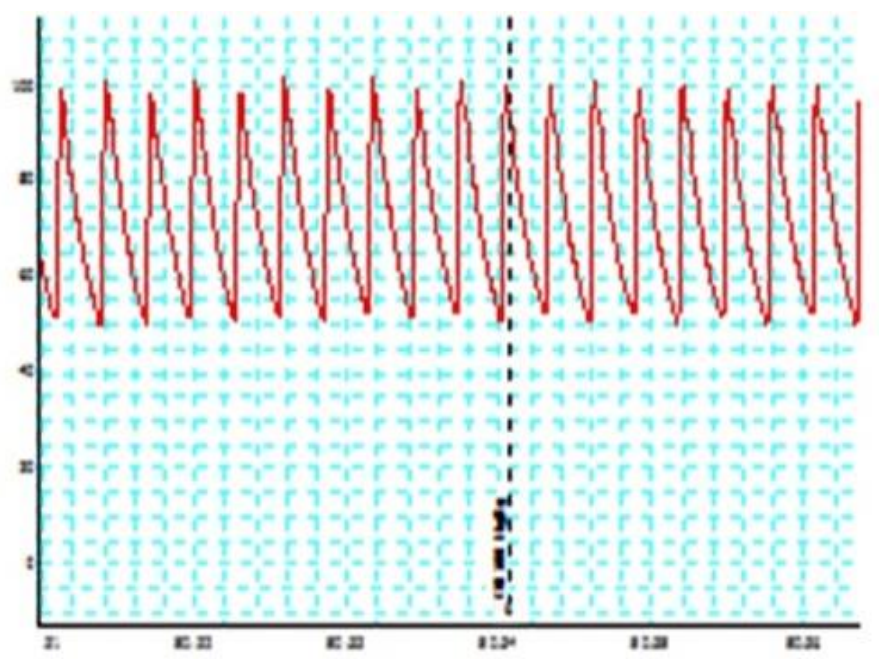

Tracing (2): Blood pressure of diabetic rat.

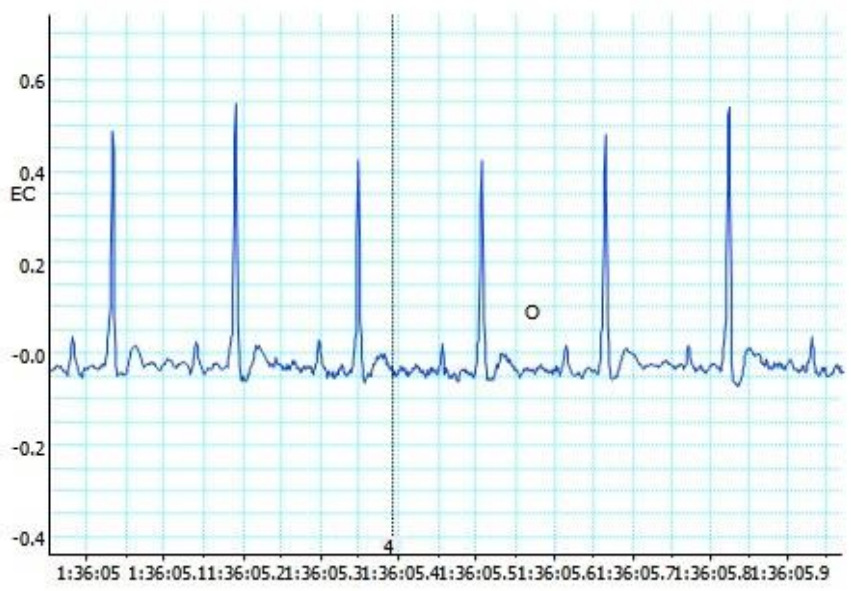

Tracing (3): ECG of normal rat. 

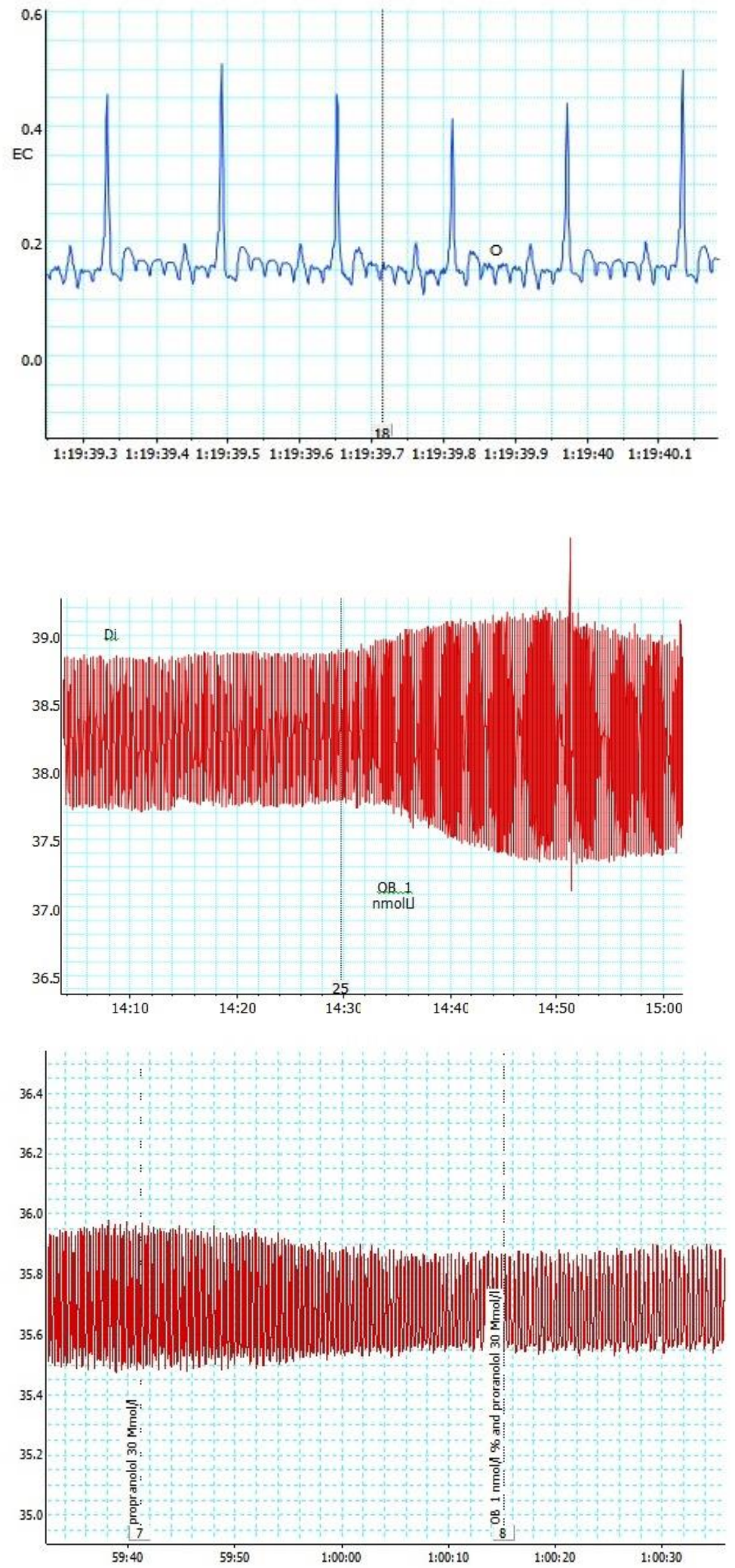

Tracing(4):ECG of diabetic rat.
Tracing (5): effect of $\mathrm{OB}$ on spontaneous contractility of isolated heart.of normal rat
Tracing (6): effect of $\mathrm{OB}$ in presence of propranolol on spontaneous contractility of isolated heart.of normal rat 


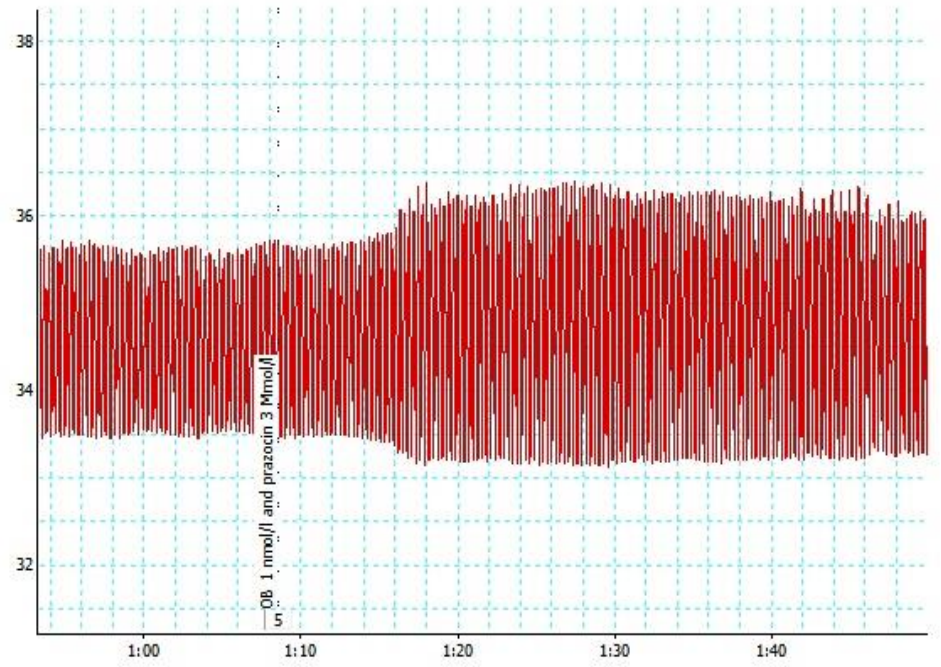

Tracing (7): effect of $\mathrm{OB}$ in presence of prazocin on spontaneous contractility of isolated heart.of normal rat

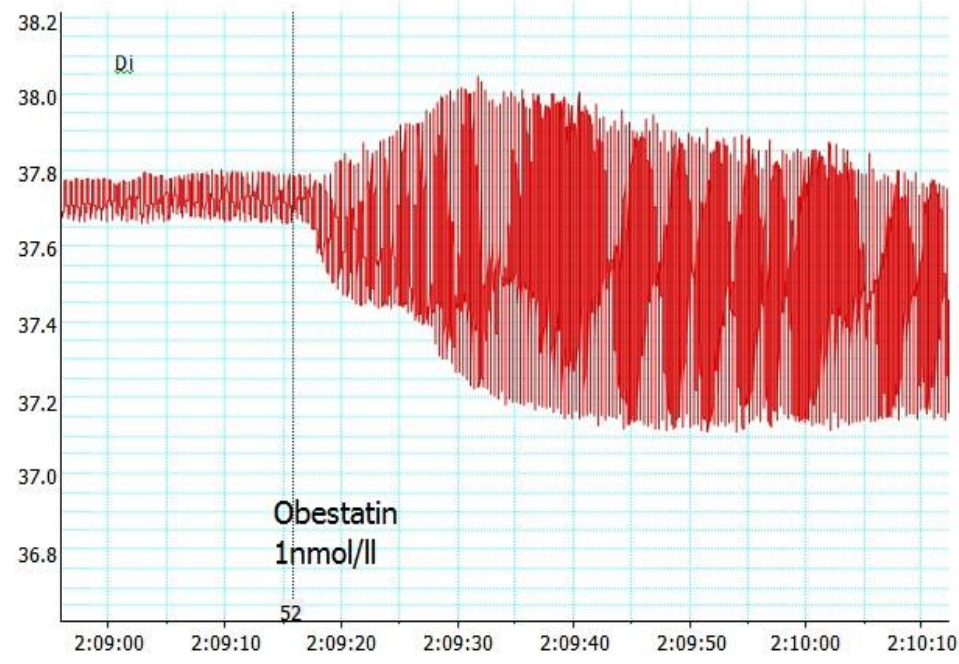

Tracing (8): effect of OB on spontaneous contractility of isolated heart.of diabetic rat

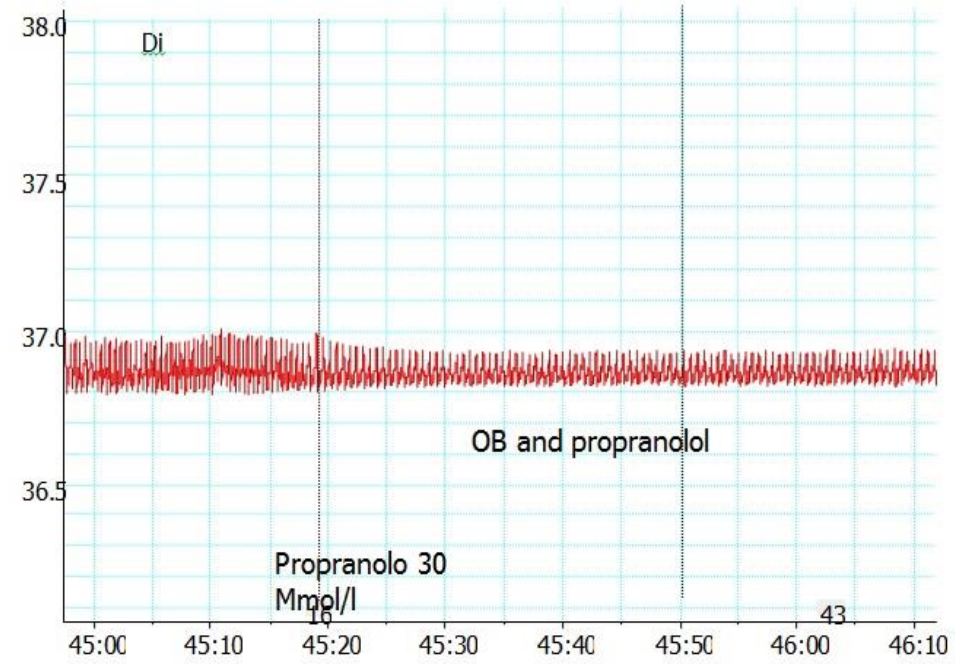

Tracing (9): effect of OB in presence of propranolol on spontaneous contractility of isolated heart of diabetic rat 


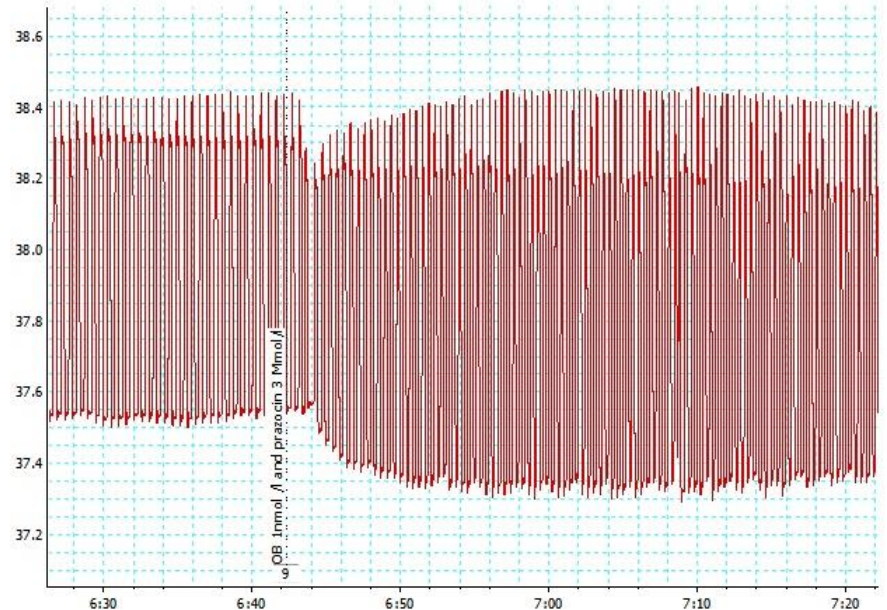

Tracing (10): effect of $\mathrm{OB}$ in presence of prazocin on spontaneous contractility of isolated heart. of diabetic rat

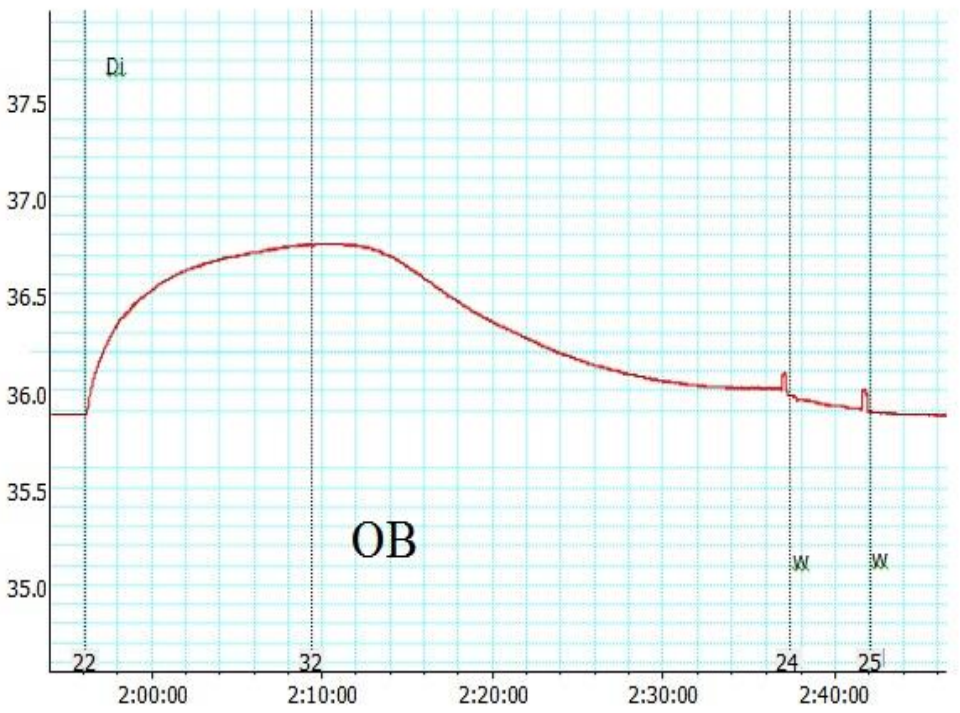

Tracing (11): effect of OB on PE induced contraction of isolated thoracic aorta of normal rat.

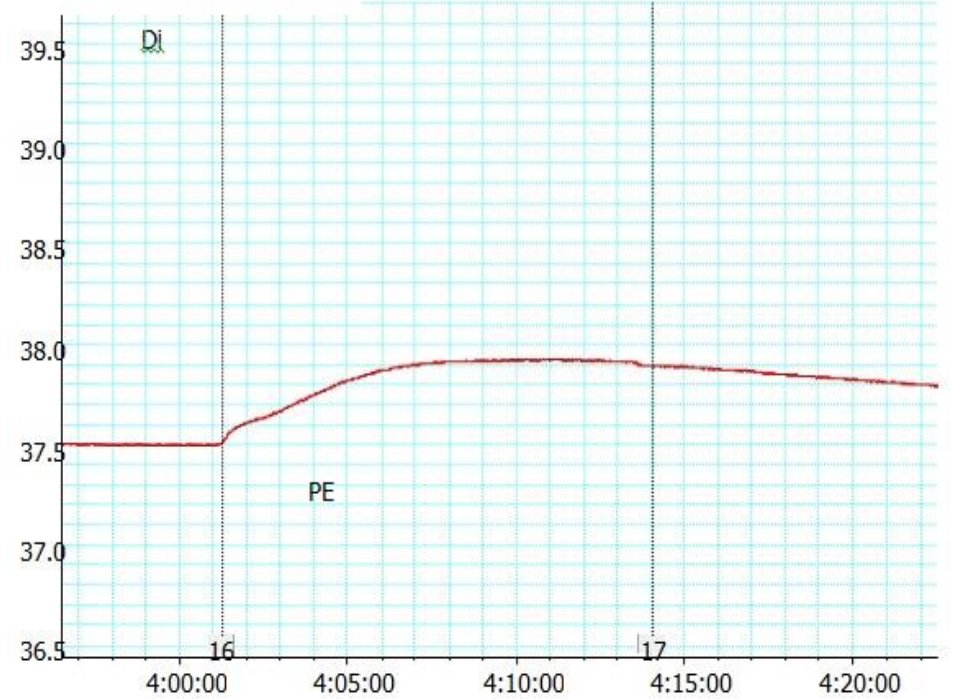

Tracing (12): effect of OB in presence of L-NAME on $\mathrm{PE}$ induced contraction of isolated thoracic aorta of normal rat. 

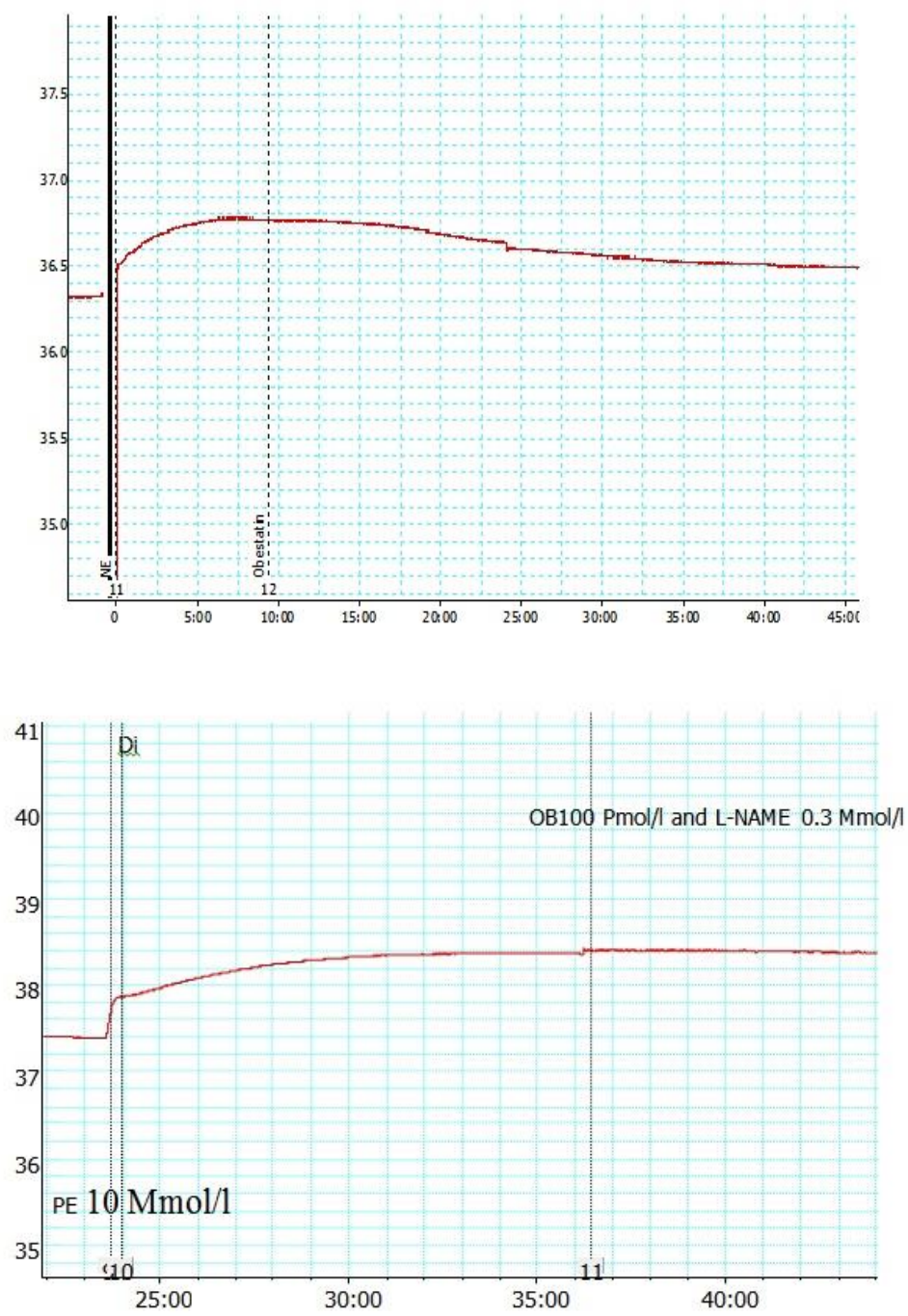

Tracing (13): effect of OB on PE induced contraction of isolated thoracic aorta of diabetic rat.
Tracing (14): effect of $\mathrm{OB}$ in presence of L-NAME on $\mathrm{PE}$ induced contraction of isolated thoracic aorta of diabetic rat.

\section{DISCUSSION}

This study has demonstrated that high-fat feeding in combination with a low dose of STZ induced type 2 diabetes model which was proved by hyperglycaemia, normoinsulinaemia and insulin resistance (increased HOMA-IR).

As regard in vivo studies, it was found that no significant effect of single $\mathrm{OB}$ injection on SBP, DBP, MAP and HR in both normal and diabetic rats.

These results come in agreement with Li et al. (19) who found that acute bolus intravenous injection of $\mathrm{OB}$ had no significant effects on MAP or HR in spontaneously hypertensive rats.
However, Anderwald-Stadler et al. (16) firstly reported that fasting plasma $\mathrm{OB}$ level was negatively correlated with SBP in insulin resistant human.

On the other hand, Ren et al., (17) showed that $\mathrm{OB}$ concentrations were positively correlated with systemic blood pressure and MAP in normal pregnant women and patients with PIH, but not in non-pregnant women. Furthermore, they found that pregnant women with PIH had significantly higher levels of OB compared with normal pregnant women. They also added that in the 3 or 5 days after delivery, there was no significant difference between 
normal pregnant women group and the $\mathrm{PIH}$ women group.

Similarly, Li et al. (18) found that fasting plasma OB levels was significantly higher in spontaneously hypertensive rats than WistarKyoto rats and they added that SBP was positively correlated with $\mathrm{OB}$ levels and they suggested that there is a disturbance of ghrelin and $\mathrm{OB}$ in the circulation of spontaneously hypertensive rats and the ghrelin/OB system might play a role in blood pressure regulation.

Furthermore, Li et al. (20) found that the fasting plasma ghrelin level and the ratio of ghrelin to $\mathrm{OB}$ were significantly lower in patients with mild to moderate untreated hypertension compared with those of the control group. They added that the fasting OB level was lower in the hypertension group compared with the control group, but the difference between them was not significant.

This discrepancy between studies could be due to the different species, cohorts studied or different pathophysiologic mechanisms between the different types of hypertension such as PIH and essential hypertension $\mathbf{L i}$ et al., (18).

The results of this study may be explained by: Firstly, most actions of obestatin occurred locally because of its short half-life in the circulation as about 2 minutes (40). Secondly, in this study we tried only intravenous injection protocol but other studies used other protocols as intraperitoneal and intracerebroventricular administration of $\mathrm{OB}$ (4). Thirdly, these results depended on acute single injection of $\mathrm{OB}$ and it is possible that chronic effect of $\mathrm{OB}$ may give different results. Fourthly, the difference of species between humans, rats and other animals may be another reason (18).

Concerning in vitro studies, it was found that basal contractility of diabetic heart was significantly decreased than that in normal rats . This finding was supported by Belke et al. (41) who found that Cardiac mechanical performance was significantly reduced in isolated diabetic rat hearts than that of the control group.

In addition, this study also found that obestatin had positive inotropic and chronotropic effects on isolated rat heart of both normal and diabetic groups by increasing significantly both the amplitude and frequency of cardiac contractility. This positive inotropic and chronotropic effects were more evident in diabetic rats when compared to the normal ones. Moreover, the effect of OB was completely abolished by pretreatment with propranolol (B blocker), while the alpha blocker prazocin didn't change the inotropic nor the chronotropic effects of OB.

These results come in accordance with Sazdova et al. (13) who applied increasing amounts of $\mathrm{OB}$ on excised frog heart preperations and found that it significantly enhanced the force and rate of their contractions. Moreover, they found that the effect of $\mathrm{OB}$ on the heart was completely inhibited by pretreatment with propranolol. While in presence of prazocin, they found that the positive inotropic and chronotropic effects were similar to $\mathrm{OB}$ application alone.

However, Iglesias et al. (12) found that exogenous $\mathrm{OB}$ had no effect on cell cycle or viability in the HL-1 cardiac muscle cell line and thought that OB was not a relevant metabolic or viability modifier for cardiomyocytes as ghrelin.

On the other hand, Argano et al. (2) recently found that $\mathrm{OB}$ displayed a beneficial effect against the alterations of contractility and $\beta$ adrenergic response in the heart of STZ treated diabetic rats. They added that there were molecular mechanisms leading to myocardial dysfunction observed in diabetic myocardial tissue include an unbalance between the prooxidant and antioxidant compounds and increased inflammatory process, in terms of TNF- $\alpha$ plasma levels and NFkB activation, so the protective effect is related to the ability of $\mathrm{OB}$ to restore oxidative balance and to promote phosphorylation/modulation of AMPK and 
prosurvival kinases such as Akt, ERK1/2 and GSK3 $\beta$.

The beneficial effect of OB could be due to its ability to counteract the switch of cardiac myosin heavy chain gene expression from the $\alpha$ - to the $\beta$-MHC isoform, and the increase of profibrogenic growth factors, such as TGF $\beta 1$ and CTGF, observed in diabetic myocardial tissue. In addition, OB was also able to restore the $\beta$-adrenergic response by promoting recovery of $\beta 1$-adrenoreceptors protein expression (2).

Therefore, it could be concluded that the positive inotropic and chronotropic effects of OB were mediated by B-adrenergic receptors and not through alpha receptors and this was supported by Sazdova et al. (13) who stated that $\mathrm{OB}$ via a Gi-protein sensitive signaling increases the release of epinephrine from heart sympathetic autonomic neurons as a neuro transmitter that act mainly via B-adrenergic receptors. Moreover, there is a complex OB receptor/ $\beta$-adrenergic receptor potentiation. And so, the observed $\mathrm{OB}$ induced $\beta$-adrenergic receptor stimulation increases the force and rate of heart contractions by many mechanisms via Gs-protein dependent stimulation of adenylate cyclase that increases the cAMP level and thus activates PKA (CAMP dependent protein kinase). PKA further phosphorylates several functionally essential cardiac proteins like Ltype $\mathrm{Ca} 2+$ channel $(\mathbf{4 2 , 4 3 )}$, ryanodine receptor (44), phospholamban, a regulatory protein of sarco-endoplasmic reticulum $\mathrm{Ca} 2+$-ATPase (45), troponin (46) and/or regulatory proteins like protein phosphatase inhibitor-1 (47), and myosin binding protein-C (48). Moreover, OB may enhance the effect of $\beta$-adrenergic signaling by up-regulating $\mathrm{B}$-adrenoreceptors (49).

As regard the effect of $\mathrm{OB}$ on blood vessels, it was found that $\mathrm{OB}$ caused significant vascular relaxation in thoracic aorta on top of $\mathrm{PE}$ induced contraction in normal rats and this relaxation was significantly attenuated by pretreatment with L-NAME. While in diabetic rats, the relaxation response of isolated thoracic aorta to OB was significantly lower than that of normal ones,. However this relaxation response was greatly abolished by L-NAME.

These results are supported by Agnew et al., (22) who found that OB exerted significant vasorelaxant effect in rat aorta which was endothelium dependent and involved production of NO (50). It can be assumed that the relaxation response of $\mathrm{OB}$ is mediated by endothelium dependent NO release via a signalling cascade involving binding to an adenylate cyclase (AC)-linked G Protein Coupled Receptor (GPCR), thereby promoting PI3K/PKB-, Ca2+-dependent eNOS activation. Relaxations mediated by $\mathrm{NO}$ are generally associated with stimulation of the cytosolic soluble guanylate cyclase in the vascular smooth muscle and the subsequent cGMP dependent activation of CGMP dependent protein kinase $\mathrm{G}$ (PKG) (51).

The involvement of this pathway in OBinduced relaxation was confirmed recently by

Agnew et al. (22) experiment with guanylate cyclase inhibitor (ODQ). PKG is then thought to mediate smooth muscle relaxation through several actions on $\mathrm{Ca} 2+$ signalling, which either lower cytosolic $\mathrm{Ca} 2+$ (e.g. increased uptake by the sarcoplasmic reticulum, inactivation of plasma membrane voltage-gated $\mathrm{Ca} 2+$ channels) or desensitize the contractile apparatus (e.g. stimulation of myosin light chain phosphatase, inhibition of Rho kinase) (52).

The endothelial damage caused by type II diabetes was proved by Xiong et al. (53) who found that endothelium-dependent vasorelaxation responses to acetylcholine were markedly attenuated in aortic rings from diabetic rats with 2 weeks duration and was retained to 4- and 8-weeks diabetic duration compared with their duration-matched control. Therefore, when NO production is greatly diminished as in type II diabetes due to endothelial damage or by application of NO blocker as L-NAME, the effect of OB will be markedly attenuated (22). 
In support with these results, Gu et al (54) deduced that the low level of plasma OB might be related to early arteriosclerosis in patients with T2DM via increasing intima-media thickness level, and elevated plasma OB levels might protect T2DM patients against carotid atherosclerosis to some extent. OB together with TNF- $\alpha$ treatment even decreased vascular cell adhesion molecule-1 expression and increase binding of LDL to macrophages, indicating the regulation of obestatin in the early atherogenic processes (55).

In conclusion, the major findings of this study is that $\mathrm{OB}$ improves cardiac performance in type II diabetes also, exerts significant vasorelaxant effects via activation of a specific endothelial NO signalling. This may not only have relevance to normal regulation of blood pressure but is likely to also extend to type II diabetes, a condition characterized by reduced endothelial NO production and the frequent development of macrovascular and microvascular complications.

\section{REFERENCES}

1-Pemberton CJ\& Richards AM: Biochemistry of ghrelin precursor peptides. Vitam Horm, 77:1330, 2008.

2- Aragno M, Mastrocola R, Ghé C, Arnoletti E, Bassino E, Alloatti G: Obestatin induced recovery of myocardial dysfunction in type 1 diabetic rats: underlying mechanisms. Cardiovasc Diabetol;11: 129-140, 2012.

3- Trovato G, Settanni F, Gesmundo L, Ghigo E, Granata R: Obestatin: is it really doing something? 42 : 175-185, 2014.

4- Zhang JV, Ren PG, Avsian-Kretchmer O, Luo $\mathrm{CW}$, Rauch R, Klein C: Obestatin, a peptide encoded by the ghrelin gene, opposes ghrelin's effects on food intake. Science 310: 996-999, 2005.

5- García EA, Korbonits, M: Ghrelin and cardiovascular health. Curr Opin Pharmacol.20:142-7, 2006.

6- Seim I, Walpole C, Amorim L, Josh P, Herington A, Chopin L: The expanding roles of the ghrelingene derived peptide obestatin in health and disease. Molecular and Cellular Endocrinology 340: 111- 117, 2011.
7- Su XJ, Rui-Xin D, Yan-Peng L, Shu-Guang Y, Zhao-Feng L: Obestatin and cardiovascular health, Peptides 52: 58-60, 2014.

8- Nagaya N, Moriya J, Yasumura Y, Uematsu M, Ono F, Shimizu W: Effects of ghrelin administration on left ventricular function, exercise capacity, andmuscle wasting in patients with chronic heart failure. Circulation;110: 3674-9, 2004.

9- Baldanzi G, Filigheddu N, Cutrupi S, Catapano F, Bonissoni S, Fubini A, Malan D, Baj G, Granata R, Broglio F, Papotti M, Surico N, Bussolino F, Isgaar J, Deghenghi R, Sinigaglia F, Prat M, Muccioli G, Ghigo E, Graziani A: Ghrelin and des-acyl ghrelin inhibit cell death in cardiomyocytes and endothelial cells through ERK1/2 and PI 3-kinase/Akt. J Cell Biol, 159:1029-1037, 2002.

10- Nagaya N, Kojima M, Uematsu M, Yamagishi M, Hosoda H, Oya $\mathrm{H}$ : Hemo-dynamic and hormonal effects of human ghrelin in healthy volunteers. Am JPhysiol Regul Integr Comp Physiol; 280:R1483-7, 2001a

11- Chang L, Ren Y, Liu X, Li WG, Yang Y, Geng B, Weintraub NL, Tang C: Protective effects of ghrelin on ischemia/reperfusion injury in isolated rat heart. J Cardiovasc Pharmacol 43: 165-170, 2004.

12- Iglesias MJ, Salgado A, Pineiro R, Otero BK, Grigorian L:. Lack of effect of the ghrelin genederived peptide obestatin on cardiomyocyte viability andmetabolism. J Endocrinol Invest;30:470-6, 2007.

13- Sazdova IV, Llieva BM, Minkov IB, Schubert R, Gagov HS: Obestatin as contractile mediator of excised frog heart. Cent Eur J Biol; 4:327-34, 2009.

14- Alloatti G, Arnoletti E, Bassino E, Penna C, Perrelli MG, Ghé C: Obestatin affords cardioprotection to the ischemic-reperfused isolated rat heart andinhibits apoptosis in cultures of similarly stressed cardiomyocytes. Am J Physiol Heart Circ Physiol;299:H470-81, 2010.

15- Laakso M: cardiovascular disease in type 2 diabetes:challenge for treatment and prevention .J Intern Med ,249:225-235,2001

16-.Anderwald-Stadler M, Krebs M, Promintzer M, Mandl M, Bischof MG, Nowotny P: Plasma obestatin is lower at fasting and not suppressed by insulin in insulin-resistant humans. Am J 
Physiol Endocrinol Metab 293: E1393-E1398, 2007.

17- Ren AJ, He Q, Shi JS, Guo ZF, Zheng X, Li L: Association of obestatin with blood pressure in the third trimesters of pregnancy. Peptides; 30:1742-5, 2009.

18- Li Z, Guo Z, Cao J, Hu J, Zhao X, Xu R: Plasma ghrelin and obestatin levels are increased in spontaneously hypertensive rats. Peptides 31: 297-300, 2010a.

19-Li Z, Song S, Qin Y, Zhang J, Zhao X, Zhang : Bolus intravenous injection of obestatin does not change blood pressure level of spontaneously hypertensive rat. Peptides; 30:1928-30, 2009.

20-Li Z, Guo Z, Yang S, Zheng X, Cao J, Qin Y: Circulating ghrelin and ghrelin to obestatin ratio are low in patients with untreated mild-tomoderate hypertension. Regul Pept 165: 206209, 2010b.

21-Ahren B. and Scheurink AJ.: Marked hyperleptinemia after high fat diet associated with severe glucose intolerance in mice. Eur $\mathbf{J}$ Endocrinol., 139: 461-467, 1998

22-Agnew AJ, Emma R, Carmel M, Adam P, Imran H, Jennifer E, Denise M, Brian D, David J: The gastrointestinal peptide obestatin induces vascular relaxation via specific activation of endothelium dependent NO signaling. British Journal of Pharmacology 166: 327-338, 2011.

23- Cha MC, Chou J , Boozer CN: High-fat diet feeding reduces the diurnal variation of plasma leptin concentration in rats. Metab., 48: 503-507, 2000.

24- Mansor LS, Gonzalez ER, Cole MA, Tyler DJ, Beeson JH, Clarke K, Carr CA, Heather LC: Cardiac metabolism in a new rat model of type 2 diabetes using high-fat diet with low dose streptozotocin, Cardiovascular Diabetology 12:136 -146,2013.

25- Yves MH and The FM: The effect of low dose insulin on mechanical sensitivity and allodynia in type 1 diabetes neuropathy. Neurose. Letters, 417: 149-154, 2007.

26- Coskun O, Ocakci A, Bayraktaroglu T, Kanter $\mathrm{M}$ : Exercise training prevents and protects streptozotocin-induced oxidative stress and betacell damage in rat pancreas. Tohoku J Exp Med., 203: 145-154, 2004.

27- Zorniak M, Mitrega K, Bialka S, Porc M, Krzeminski TF: Comparison of thiopental, urethane, and pentobarbital in the study of experimental cardiology in rats in vivo. $\mathbf{J}$ CardiovascPharmacol , 56:38-44, 2010.

28- Parasuraman $\mathrm{S}$ and Raveendran R: Measurement of invasive blood pressure in rats. Journal of pharmacololgy \& pharmaco therapeutics, 3(2):172-177, 2012.

29- Kola B, Hubina E, Tucci SA, Kirkham TC, Garcia EA, Mitchell SE, Williams LM, Hawley SA, Hardie DG, Grossman AB, Korbonits M; Cannabinoids and ghrelin have both central and peripheral metabolic and cardiac effects via AMP-activated protein kinase. J Biol Chem, 280:25196-25201, 2005.

30- Omran MA\& Abdel-Nabi IM: Changes in the arterial blood pressure, heart rate and normal ECG parameters of rat after envenomation with Egyptian cobra (Najahaje) venom. Hum Exp Toxicol , 16:327-33, 1997.

31- Ordodi VL, Mic FA, Mic AA, Toma O, Sandesc D, Paunescu V: A simple device for invasive measurement of arterial blood pressure and ECG in the anesthesized rat. Timisoara Med J, 55:357, 2005.

32- Yates MS, Askey EA, Browmer GJ: Subtype specificity of alpha adrenergic receptors in the rat heart. J. Pharm. Pharmacol.; 37: 486-490, 1985.

33- Li H, Bian J, Kwan Y, Wong T: Enhanced Responses to $17 \beta$-Estradiol in Rat Hearts Treated with Isoproterenol: Involvement of a Cyclic AMP-Dependent Pathway. J. Pharmacol. Exp. Ther.; 293: 592-598, 2000.

34- Gisclard V, Flavahan NA, Vanhoutte PM: Alpha adrenergic receptors of blood vessels of rabbits after ovariectomy and administration of $17 \beta$ estradiol. J. Pharmacol. Exp. Ther.; 240: 466-470, 1986.

35- Brawley L, Shaw AM, MacDonald A: $\beta 1$ - $\beta 2$ - and atypical $\beta$-adrenoceptor-mediated relaxation in rat isolated aorta. Br.J. Pharmacol., 129: 637-644, 2000.

36- Temple RC, Clark PM, Hales CN: Measurement of insulin secretion in type II diabetes: problems and pitfalls. Diabetic medicine, 9(6): 503-512, 1992.

37-Tietz NW, Clinical guide to laboratory tests. W.B. Saunders, Co., Philadelphia, 509-512, 1995.

38- Sun G, Bishop J, Khallili S, Vasdev S, Gill V, Pace D: Serum visfatin concentrations are 
positively correlated with serum triacylglycerols and down-regulated by overfeeding in healthy young men. Am J Clin Nutr, 85(2): 399-404, 2007.

39- Matthews DR, Hosker JP, Rudenski AS, Naylor BA, Turner RC:. Homeostasis model assessment: insulin resistance and beta-cell function from fasting plasma glucose and insulin concentrations in man. Diabetologia, 28(7):4129, 1985

40- Pan W, Tu H, Kastin A: Differential BBB interactions of three ingestive peptides: obestatin, ghrelin, and adiponectin. Peptides; 27:911-6, 2006.

41- Belke DD, Larsen TS, Gibbs EM, Severson DL: Altered metabolism causes cardiac dysfunction in perfused hearts from diabetic $(\mathrm{db} / \mathrm{db})$ mice, Am J Physiol Endocrinol Metab, 279(5):E110413,2000

42- Gerhardstein BL, Puri TS, Chien AJ, Hosey MM: Identification of the sites phosphorylated by cyclic AMP-dependent protein kinase on the s2 subunit of L-type voltage-dependent calcium channels, Biochemistry, 38, 10361-10370, 1999.

43- Nagaya N, Uematsu M, Kojima M, Date Y, Nakazato M, Okumura H: Elevated circulating level of ghrelin in cachexia associated with chronic heart failure: relationships between ghrelin and anabolic/catabolic factors, Circulation, 104, 2034-2038, 2001 b.

44- Marx SO, Reiken S, Hisamatsu Y, Jayaraman T, Burkhoff D, Rosemblit N: PKA phosphorylation dissociates FKBP12.6 from the calcium release channel (ryanodine receptor): defective regulation in failing hearts, Cell, 101, 365-376, 2000.

45- Simmerman HK and Jones L.R. Phospholamban: protein structure, mechanism of action, and role in cardiac function, Physiol. Rev.; 78, 921-947, 1998.

46- Sulakhe PV and Vo XT: Regulation of phospholamban ad troponin-I phosphorylation in the intact rat cardiomyocytes by adrenergic and cholinergic stimuli, Mol. Cell. Biochem. 149150, 103-126, 1995.

47- Zhang ZY, Zhou B, Xie L: Modulation of protein kinase signaling by protein phosphatases and inhibitors, Pharmacol. Ther.; 93, 307-317, 2002.

48- Kunst G, Kress KR, Gruen M, Uttenweiler , Gautel M, Fink RH: Myosin Binding Protein C, a Phosphorylation-Dependent Force Regulator in Muscle That Controls the Attachment of Myosin Heads by Its Interaction With Myosin S2, Circ. Res.;, 86, 51-58, 2000.

49- Liu X, Wu WK, Yu L, Li ZJ, Sung JY, Zhang ST : Epidermal growth factor-induced esophageal cancer cell proliferation requires transactivation of $\alpha$-adrenoceptors, J. Pharmacol. Exp. Ther., 326, 69-75, 2008.

50- Koc M, Kumral ZN, Ozkan N, Memi G, Kacar O, Bilsel S, Cetinel S, Yegen BC: Obestatin improves ischemia / reperfusion -induced renal injury in rats via its antioxidant and antiapoptotic effects: Role of the Nitric oxide. Peptides; $60: 23-31,2014$.

51- Moncada S, Palmer R, Higgs E: Nitric oxide: physiology, pathophysiology, and pharmacology. Pharmacol Rev 43: 109-142, 1991.

52-Lincoln T, Dey N, Sellak H: Invited review: cGMP-dependent protein kinase signaling mechanisms in smooth muscle: from the regulation of tone to gene expression. J Appl Physiol 91: 1421-1430, 2001

53- Xiong Y, Lei M, Fu S, Fu Y:Effect of diabetic duration on serum concentrations of endogenous inhibitor of nitric oxide synthase in patients and rats with diabetes, Life Sciences 77(2) :149$159,2005$.

54-Gu PY, Kang DM, Wang WD, Chen Y, Zhao $\mathrm{ZH}$, Zheng $\mathrm{H}$, Ye SD:

Relevance of plasma obestatin and early arteriosclerosis in patients with type 2 diabetes mellitus. Journal of Diabetes Research Volume 2013, Article ID 563919, 6 pages, 2013.

55-Kellokoski E, Kunnari A, Jokela M, Makela S, Kesaniemi YA, and orkk"o SH, :Ghrelin and obestatin modulate early atherogenic processes on cells: enhancement of monocyte adhesion and oxidized low-density lipoprotein binding," Metabolism, vol. 58, no. 11, pp. 1572-1580, 2009. 